\title{
Spatial modeling of mortality from acute lower respiratory infections in children under 5 years of age in 2000-2017: a global study
}

\author{
Ali Almasi, $\mathrm{PhD}^{1}$, Sohyla Reshadat, $\mathrm{PhD}^{1}$, Alireza Zangeneh, MSc ${ }^{1}$, Mehdi Khezeli, $\mathrm{PhD}^{1}$, Raziyeh Teimouri, PhD ${ }^{2}, \mathrm{Samira}$ \\ Rahimi Naderi, $\mathrm{MSc}^{3}$, Shahram Saeidi, $\mathrm{MSc}^{1}$ \\ ${ }^{1}$ Social Development \& Health Promotion Research Center, Health Institute, Kermanshah University of Medical Sciences, Kermanshah, Iran; ${ }^{2}$ Department of Art, \\ Architecture and Design, University of South Australia, Adelaide, Australia; ${ }^{3}$ Department of Nursing, School of Nursing and Midwifery, Hamadan University of \\ Medical Sciences, Hamadan, Iran
}

Background: Over the past few decades, various goals have been defined to reduce the mortality of children caused by acute lower respiratory infections (ALRIs) worldwide. However, few spatial studies to date have reported on ALRI deaths.

Purpose: We aimed to assess the spatial modeling of mortality from ALRI in children under 5 years of age during 2000-2017 using a global data.

Methods: The data on the mortality of children under 5 years old caused by ALRI were initially obtained from the official website of the World Health Organization. The income status of their home countries was also gathered from the Country Income Groups (World Bank Classification) website and divided into 5 categories. After that, in the ArcGIS 10.6 environment, a database was created and the statistical tests and related maps were extracted. The Global Moran's I statistic, Getis-Ord Gi statistic, and geographically weighted regression were used for the analyses. In this study, higher $\mathrm{z}$ scores indicated the hot spots, while lower $z$ scores indicated the cold spots.

Results: In 2000-2017, child mortality showed a downward trend from 17.6 per 100,000 children to 8.1 and had a clustered pattern. Hot spots were concentrated in Asia in 2000 but shifted toward African countries by 2017. A cold spot that formed in Europe in 2007 showed an ascending trend by 2017. Based on the results of geographically weighted regression test, the regions identified as the hot spots of mortality from ALRI in children under 5 years old were among the middle-income countries $\left(R^{2}=0.01\right.$, adjusted $\left.R^{2}=8.77\right)$.

Conclusion: While the total number of child deaths in 2000 2017 has decreased, the number of hot spots has increased among countries. This study also concluded that, during the study period, Central and Western Africa countries became the main new hot spots of deaths from ALRI.

Key words: Geographic information system, Mortality, Respiration Disorders

\section{Key message}

Question: We assessed the spatial modeling of mortality from acute lower respiratory infections in children under 5 years old during 2000-2017 using a global data.

Finding: The total number of child deaths during the study period decreased, while the number of hot spots increased among countries.

Meaning: Hot spots were concentrated in Asia in 2000 but shifted toward African countries by 2017. A cold spot formed in Europe over the study period.

\section{Introduction}

Ever since the World Summit for Children held in 1990, there has been a strong desire to consider the child mortality rate as an index for health and human development. ${ }^{1)}$ According to the World Health Organization (WHO) and United Nations Children's Emergency Fund, 5.4 million of children under 5 years died in $2017 .{ }^{2)}$ Globally, it is estimated that 60,000 children die before the age of 5 from lower respiratory infections (LRIs) caused by second-hand smoke. Health consequences of secondhand smoke exposure can continue to adulthood, so that LRIs in early childhood significantly increase risk of developing chronic obstructive pulmonary disease in adulthood. ${ }^{3)}$

Over the past decade, various goals have been defined to reduce global child mortality. For example, Sustainable Development Goals (SDGs) specify that all countries should reduce the under-five child mortality to 25 per 1,000 live births by 2030.4) Although the number of new cases of respiratory infections in children varies in countries and different regions of the world, 5) its mortality rate is one of the highest among the causes of childhood death in the world. ${ }^{6}$ ) In this regard, the spatiotemporal analysis of infectious diseases has been considered as one of the effective methods of etiology of diseases. ${ }^{7)}$ It should be noted

Corresponding author: Shahram Saeidi, MSc, Social Development \& Health Promotion Research Center, Health Institute, Kermanshah University of Medical Sciences, Shahid Beheshti Blvd- Laleh alley, Kermanshah, Iran 
Global study

\section{Mortality from Acute Lower Respiratory Infections} in Children < 5 years Old $(2000-2017)$

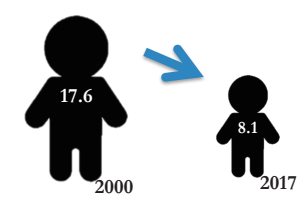

Mortality change

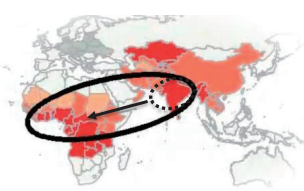

Trend of hot spots 2000 to 2017

\section{Summary}

Child mortality showed a downward trend from 17.6 to 8.1 per 100,000 children.

Child mortality caused by ALRI had a clustered pattern

; Hot spots were shifted from Asia toward Africa.

Regions identified as the hot spots of mortality from ALRI in children under 5 years were among the middle-income countries $\left(R^{2}=0.01\right.$ and Adjusted $\left.R^{2}=8.77\right)$.

Graphical abstract

that there is growing evidence that the dynamic spatial data are a key element in monitoring and anticipating the spread of epidemics. ${ }^{8)}$

Spatial distribution of respiratory diseases has been less studied despite its considerable geographical variation. ${ }^{9)}$ However, understanding the spatial diversity of respiratory diseases can provide a proper basis for targeted preventive interventions. To this end, the areas where the hot spots of the disease and mortality are concentrated should be specifically examined. ${ }^{10)}$

Geographic information system (GIS), which features the ability to understand geometric patterns in space and time can be used to investigate the hot spots and periodic changes of mortality. ${ }^{11)}$ GIS is a potentially useful tool for assessing various aspects of health, whose features include the ability to integrate data from different sources to generate new information and intrinsic visualization applications. It also has lasting effects on the public health by offering creative solutions for problems. ${ }^{12)}$ Although various studies have been conducted about mortality and infectious diseases, few spatial studies have been done about the mortality from respiratory infections. ${ }^{13)}$ Hence, knowing about the changes in hot spots can play a key role in health planning in the future. Therefore, this study aimed to present the spatial modeling of mortality from ALRI in children under 5 years of age in 2000-2017: a global study.

\section{Methods}

In this descriptive study, data on mortality of children under 5 years caused by ALRI were obtained as a tabular file (Excel format) through the WHO website (http://who.int/entity/gho/ publications/world_health_statistics/2017/en/index.html). In the next step, a code from 1 to 194 was defined for each country in Excel 2007. Then the geographic information system
(ArcGIS 10.6) was used for spatial modeling. For this purpose, a geo-database was created in Arc-Catalog software, then using the capabilities of GIS, a code from 1 to 194 was defined for the tables of spatial layers of countries. In the next step, the coded Excel files were joined to the coded spatial layers of each country using the Join command. Then, in ArcMap software environment, spatial tests and related maps were extracted. To spatial analysis of ALRI in children under 5 years of age, we used the spatial auto-correlation analysis (Global Moran's I, GMI), Getis-Ord Gi (GOG) statistic, and geographically weighted regression (GWR).

GMI is calculated as follows (Equation 1-1 to 1-4):

$$
\begin{gathered}
I=\frac{\mathrm{n}}{\mathrm{S} 0} \frac{\mathrm{n} \sum_{\mathrm{i}=1}^{\mathrm{n}} \sum_{j=1}^{\mathrm{n}} W \mathrm{i}, \mathrm{jZiZj}}{\sum_{\mathrm{i}=1}^{\mathrm{n}} \mathrm{Z}_{\mathrm{i}}^{2}} \\
\mathrm{~S}_{0}=\sum_{i=1}^{n} \sum^{\mathrm{n}} \mathrm{Wi}, \mathrm{j} \\
Z_{1}=\frac{1-E[I]}{\sqrt{V[I]}} \\
E[I]=-1 /(n-1) \\
V[I]=E\left[I^{2}\right]-E[I]^{2}
\end{gathered}
$$

Where $\mathrm{Xi}$ and $\mathrm{Xj}$ represent the variable values in the locations $i$ and $j$. In addition, $X$ shows the average of the attributes of each location, and Wij is the spatial weight of $i$ and $j$. If $i$ and $j$ are in the neighborhood of each other, the Wij value equals one, otherwise, the value equals zero. Moreover, S0 denotes the sum of all the elements.

To determine the spatial distribution of hot spots (spatial clusters with large values) and cold spots (spatial clusters with low values), the GOG statistic was used (Equations 2-1 to 2-3): 


$$
\begin{gathered}
G_{i}^{*}(d)=\frac{\sum_{j W_{j}(d) X_{j}-\mathrm{W}^{* i} X^{*}}-}{\left.S^{*}\left\{\left[\left(\delta^{*} 1 i\right)-W_{i}^{* 2}\right] /(n-1)\right\}\right)^{1 / 2}} \\
\bar{X}=\frac{\sum_{j=1}^{n} X j}{n} \\
s=\sqrt{\frac{\sum_{j=1}^{n} X_{j}^{2}}{n}-(\bar{X})^{2}}
\end{gathered}
$$

(Equation 2-1)

(Equation 2-3)

Where $\mathrm{Xj}$ is the value for element $\mathrm{j}, \mathrm{W}_{\mathrm{ij}}$ denotes the spatial weight between the elements and each of $i$ and $j$, and finally $n$ represents the total number of elements. Moreover, the value of this statistic ranges from \pm 1 to \pm 3 at $90 \%, 95 \%$, and $99 \%$ confidence levels.

Additionally, to evaluate the trend of disease hot spots, the Spatial Deviational Ellipse was employed (Equations 3-1 and $3-2)$ :

$$
\begin{gathered}
C=\left(\begin{array}{cc}
(\operatorname{Uar}(x) & \operatorname{Cov}(x, y) \\
\operatorname{Cov}(y, x) & \operatorname{Uar}(y)
\end{array}\right)=\frac{1}{n}\left(\begin{array}{cc}
\sum_{i=1}^{n} \tilde{x}_{i}^{2} & \sum_{i=1}^{n} \tilde{x}_{i} \tilde{y}_{i} \\
\sum_{i=1}^{n} \tilde{x}_{i} \tilde{y}_{i} & \sum_{i=1}^{n} \tilde{y}_{i}^{2}
\end{array}\right) \quad \text { where, } \\
\operatorname{uar}(x)=\frac{1}{n} \sum_{i=1}^{n}(x i-\bar{x})^{2}=\frac{1}{n} \sum_{i=1}^{n} \tilde{x}_{i}^{2} \\
\operatorname{cov}(x, y)=\frac{1}{n} \sum_{i=1}^{n}\left(x_{i}-\bar{x}\right)\left(y_{i}-\bar{y}\right)=\frac{1}{n} \sum_{i=1}^{n} \tilde{x}_{i} \tilde{y}_{i} \\
\operatorname{uar}(y)=\frac{1}{n} \sum_{i=1}^{n}\left(y_{i}-\bar{y}\right)^{2}=\frac{1}{n} \sum_{i=1}^{n} \tilde{y}_{i}^{2}
\end{gathered}
$$

$\sigma_{1,2}=\left(\frac{\left(\sum_{i=1}^{n} \tilde{x}_{i}^{2}+\sum_{i=1}^{n} \tilde{y}_{i}^{2}\right) \pm \sqrt{\left(\sum_{i=1}^{n} \tilde{x}_{i}^{2}+\sum_{i=1}^{n} \tilde{y}_{i}^{2}\right)^{2}+4\left(\sum_{i=1}^{n} \tilde{x}_{i} \tilde{y}_{i}\right)}}{2 n}\right)^{1 / 2}$

(Equation 3-1)

(Equation 3-2)

In this equation, $x i$ and yi are the coordinates of element $i$, and $\bar{X}$ and $\bar{Y}$ represent the central mean of elements, respectively. Moreover, $\mathrm{n}$ denotes the total number of elements in the layer. After calculating the mean scores and standard deviations, some points were determined in each direction based on the standard deviation, which was then connected together.

Further, GWR was used for assessing the association between child mortality and income status of countries. This regression depends on the spatial coordinates (spatial and geographic weights), with their values and signs having spatial variability. The GWR formula is as follows (Equation 4):

$$
\begin{gathered}
\dot{y}=\beta 0(\dot{u}, \dot{v})+\sum \beta o(\dot{u}, \dot{v}) X i k+€ \\
i=1,2, \ldots n
\end{gathered}
$$

In this equation, (vi, ui) forms the coordinates of the i-th point in space, $\beta$ (ui,vi) is a continuous function of $\mathrm{K}(\mathrm{v}, \mathrm{u}$ ), and wherever $\beta$ is at each point of $i$, the explanatory variables of $\mathrm{Xi1}$, ...., Xip are regarded as errors at points $i$ and $€$ i. For the given data set of the regional parameters $K(v, u), \beta$ is estimated using the weighted least squares. The $\mathrm{Wij}_{\mathrm{ij}}$ weights in each position (vi, ui) for $i=1,2 \ldots, n$ are obtained as a continuous function of the intervals between points $i$ and other data points.

\section{Results}

In Fig. 1, between the years 2000 and 2017, child mortality showed a downward trend from 17.6 per 100000 children to 8.1.

Fig. 2 shows the trend of mortality from ALRI in children under 5 years among countries. The countries with the highest and lowest numbers of mortality are in red and blue colors, respectively. Further, in 2000, the highest numbers of child mortality from the ALRI were in India, China, Afghanistan, Pakistan, Nigeria, and Ethiopia. However, India, Chad, Central Africa, and Nigeria had the highest numbers of child mortality from this disease in 2017. Based on Fig. 2, China experienced a decline from the orange level in 2000-2004 to yellow in 20052013, and then in 2014-2017, it changed to light blue which indicates a significant reduction in deaths due to ALRI.

As shown in Fig. 3, the mortality of children under 5 years caused by ALRI has followed a clustered pattern over 2000 2017 (Moran's $I>0$ and $z$ score $>2.58$ ).

Fig. 4 shows the results of the GOG statistic for the identification of hot and cold spots of mortality of children under 5 years caused by ALRI at 90\%, 95\%, and 99\% confidence

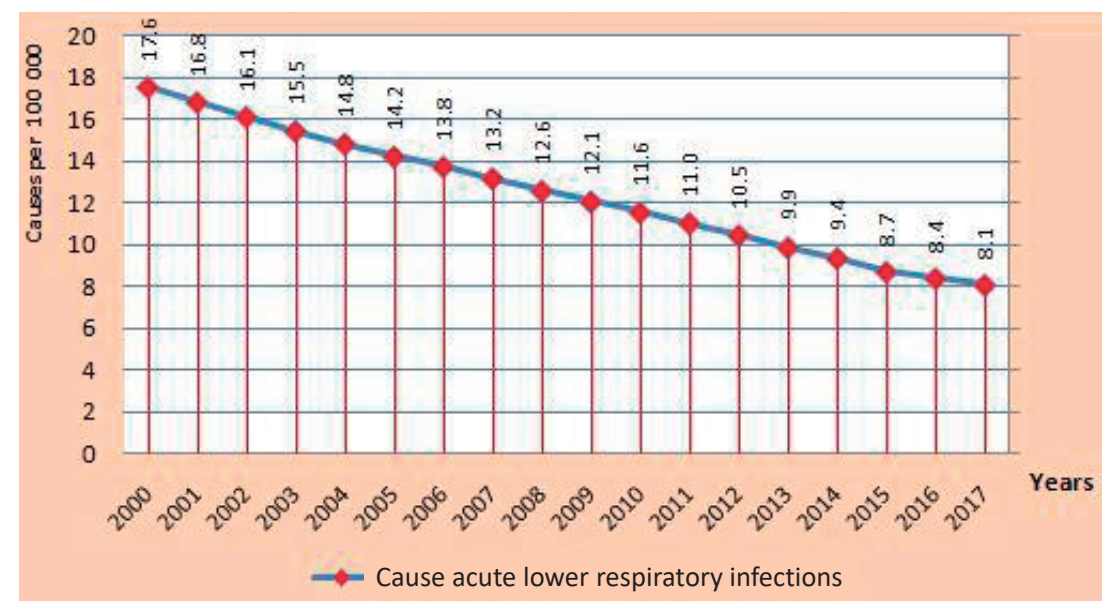

Fig. 1. The number of cases of mortality from acute lower respiratory infections in children under 5 years old per 100,000 children in 2000-2017. 


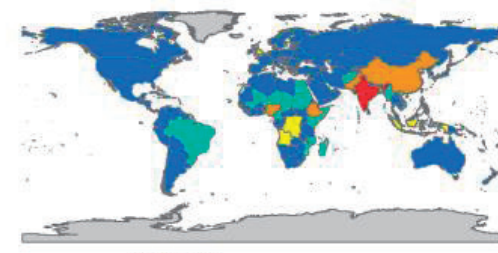

2000

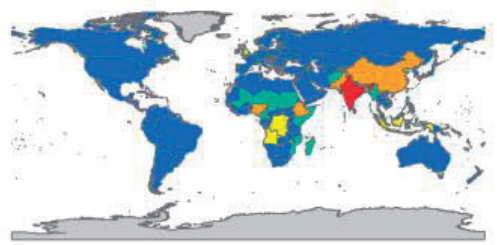

2003

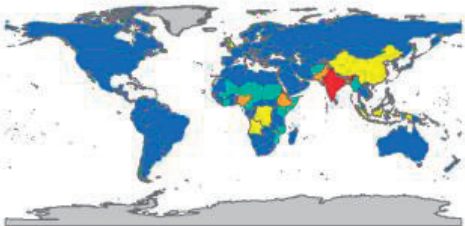

2006

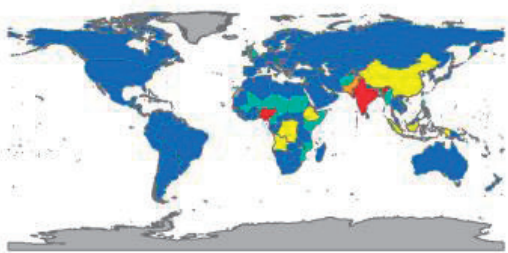

2009

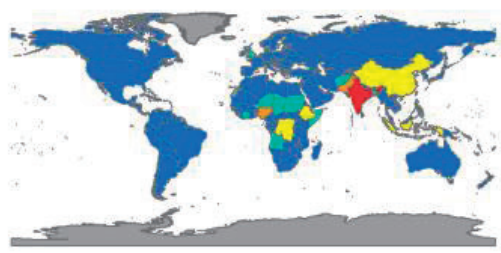

2012

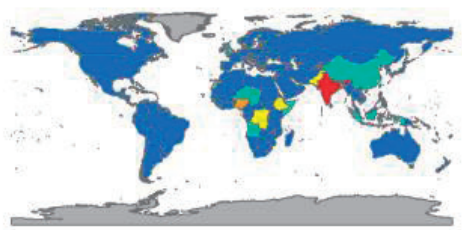

2015

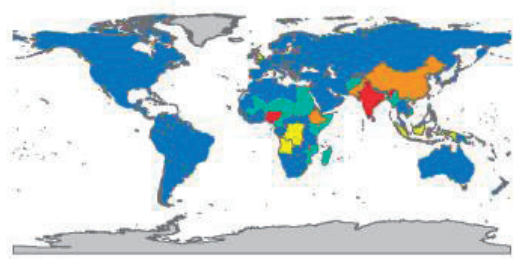

2001

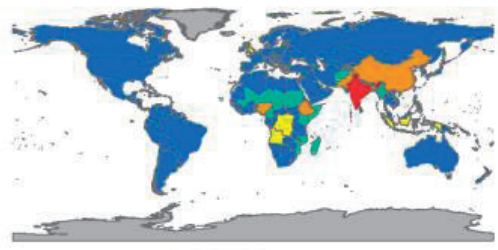

2004

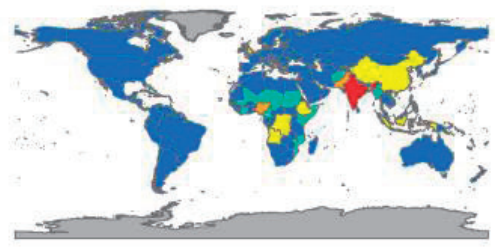

2007

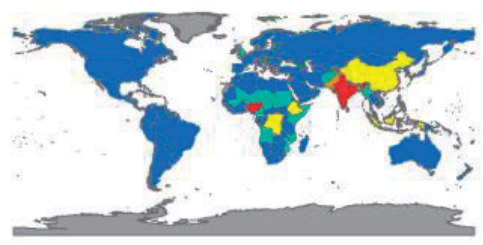

2010

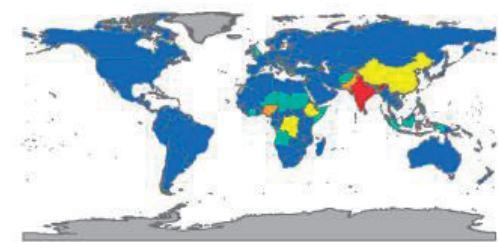

2013

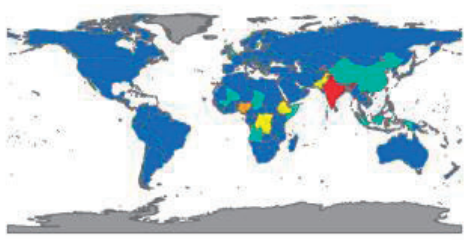

2016

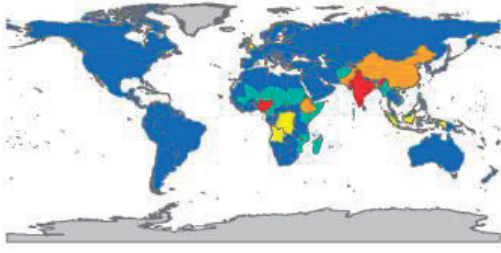

2002

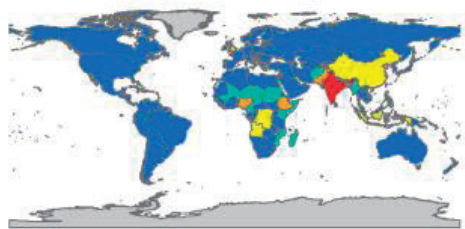

2005

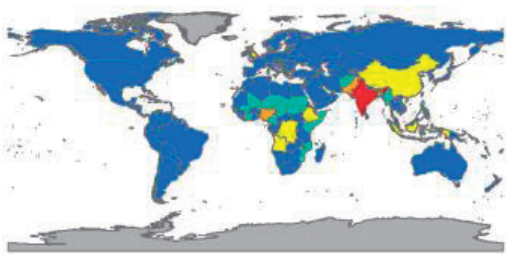

2008

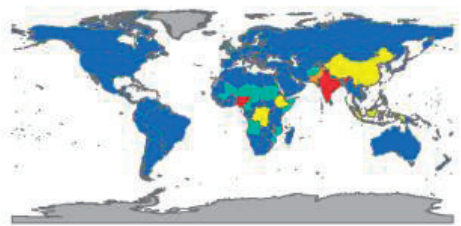

2011

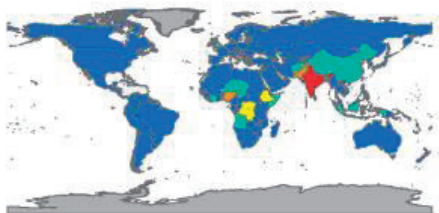

2014

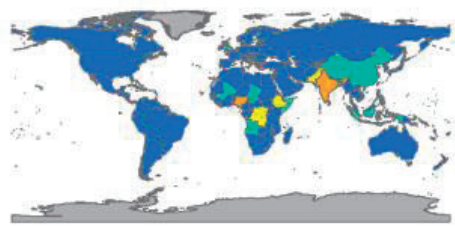

2017

Legend

Mortality in children under 5 years

Number

NoData

$1-6534$

$6534-12869$

$12869-31804$

प $31804-75297$

$75297-243568$

Fig. 2. Trends in mortality from acute lower respiratory infection in children under 5 years old in 2000-2017. 


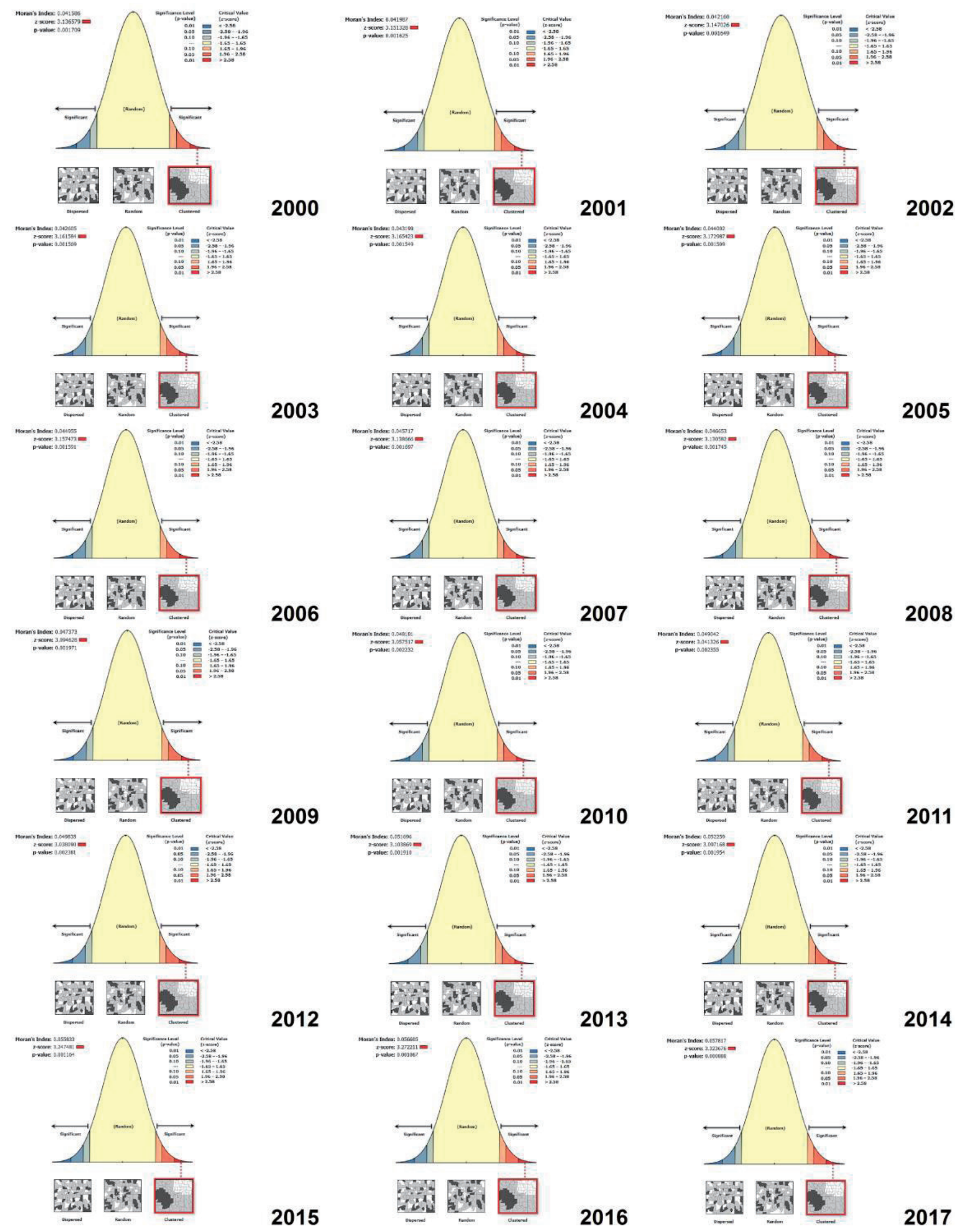

Fig. 3. Global Moran's I test results for identifying the mortality clusters of children under 5 years old caused by acute lower respiratory infection. 

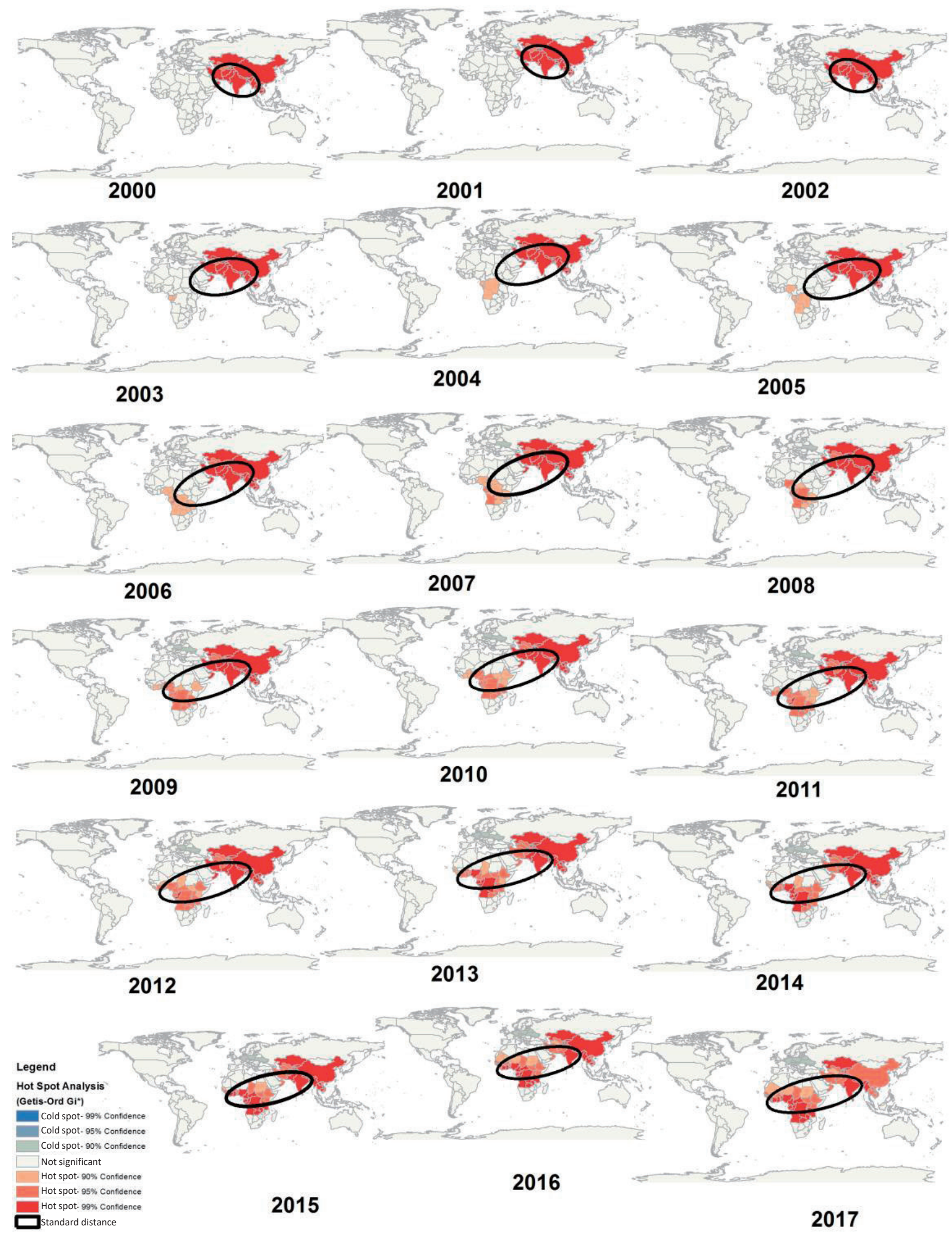

Fig. 4. The spatial trends of the hot and cold spots of mortality from acute lower respiratory infection in children under 5 years old during the study period. While hot spots were concentrated in Asia in 2000, a shift occurred toward African countries by 2017. 
levels. The results demonstrated that the hot spots were concentrated in Asia in 2000 (China, Thailand, Myanmar, India, Pakistan, Afghanistan, Kyrgyzstan, Uzbekistan, Turkmenistan, Kazakhstan, Iran, and Oman), while within 18 years, it drew towards the African countries (Angola, Tanzania, Zaire, Kenya, Ethiopia, Sudan, Chad, Nigeria, Cameroon, Congo, Central Africa, Mali, Ghana, Ivory Coast, Guinea, Senegal, Mauritania). It should be noted that a cold spot was formed in Europe from 2007 onward and followed an ascending trend by 2017. Based on the GIS maps, the direction of focal points has undergone changes, so that the direction has been northwestsoutheast in the years 2000, 2001, and 2002, whereas changing in a northeast - southwest direction from 2003 onward. Other findings showed that in 2000, 25 countries were identified as hot spots, which increased to 60 countries in 2017 (Fig. 5).

As shown in Fig. 6, based on the results of GWR test, the regions identified as the hot spots of mortality from ALRI in children under 5 years were among the middle-income countries $\left(R^{2}=0.01\right.$, adjusted $\left.R^{2}=8.77\right)$.

\section{Discussion}

The present study provides the spatial modeling of mortality from ALRI in children under 5 years residing in 194 countries over 2000-2017. Based on the results, the total number of children mortality from ALRI followed a downward trend during the 18-year period of the study. This finding was consistent with the results of studies conducted by Roth et al., ${ }^{8)}$ Błażejczyk et al. ${ }^{14)}$ Although the results of the present study indicated a decrease in the number of child mortality, respiratory infections are still the third leading cause of childhood mortality ${ }^{15}$ ) which should be addressed by health interventions. Therefore, there should be health plans and policies consistent with the aim of SDGs to reducing child mortality up to 25 per

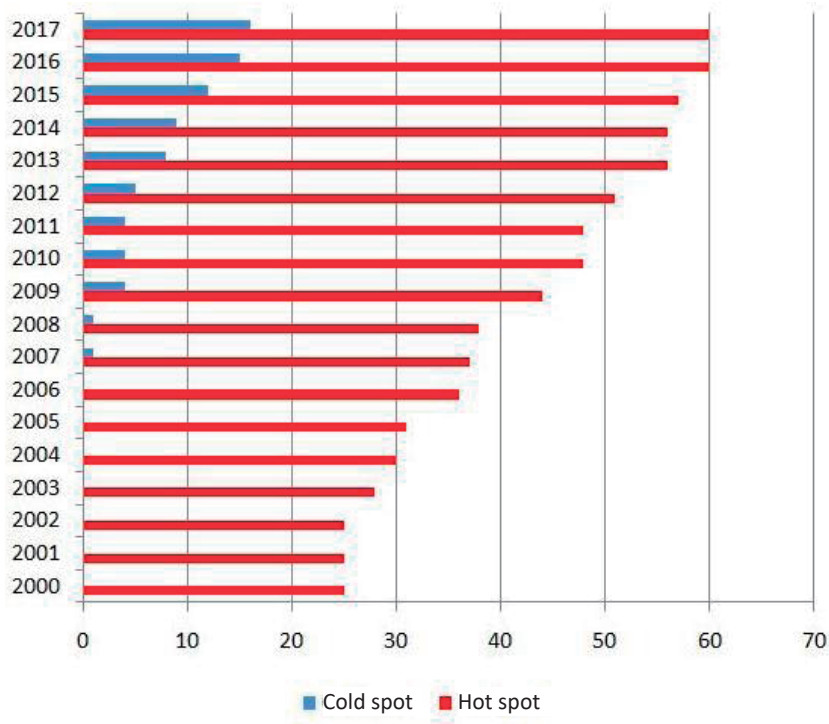

Fig. 5. The number of hot and cold spots of mortality from acute lower respiratory infection in children under 5 years old.
1,000 live births by $2030{ }^{16)}$

The results also showed that the mortality from ALRI in children under 5 years was clustered and had some foci in the world (Fig. 3). These results were consistent with those reported by Golding et al. ${ }^{17)}$ in Africa. Differences between countries can be due to climate, ${ }^{18)}$ health infrastructure, ${ }^{19)}$ urban traffic, ${ }^{20)}$ latitude and longitude, ${ }^{21)}$ low education of mothers. ${ }^{22)}$ In addition to the above-mentioned factors, indoor and outdoor air pollution $^{23)}$ should be also considered which affects around 600,000 children around the world annually. ${ }^{3)}$ In a study conducted by $\mathrm{Yu}$ et al., ${ }^{24)}$ the effects of dust storms on Asian students' respiration were highlighted. In addition, Analitis et al. ${ }^{25)}$ studied the relationship between temperature and mortality from respiratory infections, in which $1^{\circ} \mathrm{C}$ rise in the temperature led to a $3.3 \%$ increase in respiratory mortality.

According to our findings, most of the hot spots of ALRI in children under 5 in 2000 were concentrated in Asian countries such as China, Thailand, Myanmar, India, Pakistan, Afghanistan, Iran, and Central Oman. During the18-year period of study, in addition to Asian countries, hot spots have spread to African countries such as Kenya, Ethiopia, Sudan, Nigeria, Chad, Congo, Central Africa, Ghana, and Mauritania (Fig. 4). A similar study by Reiner et al., ${ }^{26)}$ used Bayesian geostatistical modeling to estimate Lower respiratory infections (LRI) incidence, prevalence, and mortality in African children from 2000 to 2017. The results of that study showed that the distribution of LRI cases and deaths in Central Africa was higher than in other continental countries. Similarly, our study showed that in 2017, the death foci of ALRI were in Central African countries. However, the present study, which examined the trend of deaths in the world, showed the general picture of the morbidity situation caused by ALRI in different continents and suggested that the death foci have shifted from Asia to Africa. It should also be noted that in the study of Reiner et al. ${ }^{26)}$ both incidence and mortality were studied, but in our study, only mortality was examined. The results of the present study also were consistent with those reported by Golding et al. ${ }^{17)}$ in terms of the spread of the mortality hot spots towards the central and western parts of the Africa continent. It seems that the movement of children mortality hot spots from Asia to Africa over the past 18 years has resulted from various reasons, including the spread of the disease in developing countries, ${ }^{13)}$ improving the death data registry system in African countries, ${ }^{27)}$ global climate change, ${ }^{28)}$ and environmental pollution and dust. ${ }^{29)}$ Accordingly, health policy makers should pay particular attention to several countries. One of these countries is India, which has had the highest mortality rates in the last 18 years, thus causing problems. ${ }^{23)}$ Furthermore, Chad and Central Africa, as the hot spots of mortality from ALRI, receive less funding from the international organizations for health. ${ }^{17)}$

According to the findings of the present study, new cold spots were formed in Europe 2007, and have expanded by 2017. In a study by Brownell et al., ${ }^{30)}$ the evidence pointed out the reduction of child mortality in high-income countries, which 


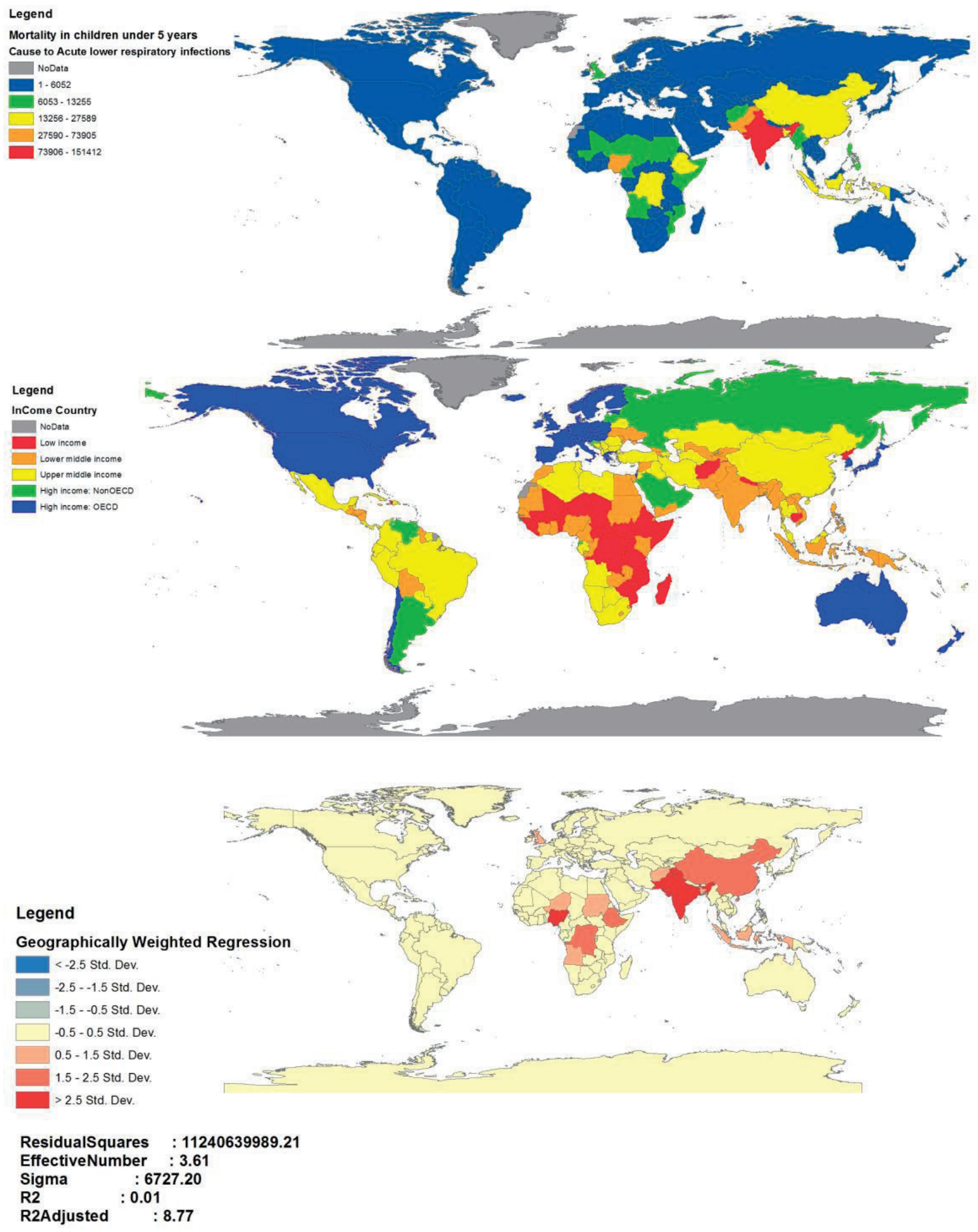

Fig. 6. Correlations between country income status and mortality from acute lower respiratory infection in children under 5 years old. 
seems to be influenced by the income conditions and the level of development in the European countries. ${ }^{31)}$

Based on the results, the spatial direction of hot spots concentrated northwest-southeast in 2000 to 2002, whereas changing in a northeast - southwest direction from 2003 onward (Fig. 4). In the whole period under study, the spatial direction of hot spots overlapped in developing countries, and the common feature of countries with hot spots was their development status. The early diagnosis and treatment of respiratory infections among developing countries have also been emphasized by the WHO. For example, Bangladesh can be referred to as a model among developing countries that has implemented a systematic reporting in the country. The capability of this program is quick monitoring and access to electronic data for further analysis. ${ }^{13)}$

The results of the present study also indicated the increasing trend in hot spots of children mortality in countries, so that 25 countries were recognized as hot spots in 2000, which increased to 60 countries in 2017 (Fig. 5). However, child mortality rates have declined. Although, health policies seem to have been able to reduce mortality in children under the age of 5 , but still in developing countries, the mortality due to acute respiratory infections is on the rise. In other studies, spatial distribution and clustering of respiratory diseases have been addressed such as Netherlands ${ }^{20)}$ and Iran. ${ }^{32)}$ Although the geographic area of these studies was not comparable to our research, they were similar in terms of using the same spatial statistics methods.

Based on the results of the GWR test, the countries that were introduced as the hot spots of ALRI in children were among the middle-income countries (Fig. 6). These results were consistent with the results of a study conducted in 17 countries of the Middle East and North Africa over 1980-2010 ${ }^{33)}$ and a study carried out in 59 less-developed countries in $1991{ }^{34)}$ Furthermore, in studies done by Sonego et al., ${ }^{35)}$ the relationship between low socioeconomic status and the risk of respiratory infections has been addressed. Given that the mortality of children under 5 years is expected to increase in middle-income countries,${ }^{10)}$ this will have important implications for services in middle-income countries, in addition to low-income countries. In addition, understanding the effects of the socioeconomic status of countries is complex and needs to be further explored. However, the present study can provide a suitable model for preventive decisions and the possibility of allocating resources.

One of the limitations of the present study was the use of secondary data, which made it impossible to investigate the quality of data for researchers. There were also differences in the methods of collecting information and estimates of the number of deaths in countries, which was beyond the control of researchers. In this study, the researchers failed to measure the effective factors and causes of ALRI on child mortality due to lack of access to specific indicators such as children's exposure to unhealthy weather, dust storms, and traffic across countries. Therefore, it is recommended that the data of mortality from respiratory diseases be collected with careful consideration and attention nationally and internationally.
In conclusion, the findings of the present study demonstrated that the total number of child mortality over 2000-2017 followed a downward trend, while the number of hot spots increased among countries. It was also found that the mortality of children under 5 years caused by ALRI has followed a clustered pattern, and the situation has taken the form of hot and cold spots in different countries, drawing from the Asian countries (main hot spots in 2000) towards the African countries (over the 18 years under study). In fact, the present study allows the health planners and policy makers to use the GIS visual statistics, information, and rapid identification of the distribution of mortality from acute infections, rather than using the statistical tables that are difficult to understand. Moreover, health policy makers are recommended to pay special attention to countries that have been introduced as hot spots. It is also suggested that the relationship between child mortality from ALRI and climate change, dust storms, traffic and socioeconomic conditions be addressed in future studies.

\section{Footnotes}

Conflicts of interest: No potential conflict of interest relevant to this article was reported.

\section{ORCID:}

Ali Almasi (ํ) https://orcid.org/0000-0002-1506-7289

Sohyla Reshadat 10 https://orcid.org/0000-0001-6160-3268

Alireza Zangeneh 10 https://orcid.org/0000-0001-9692-9655

Mehdi Khezeli @ https://orcid.org/0000-0001-9372-4224

Raziyeh Teimouri $\odot$ https://orcid.org/0000-0001-9387-8362

Shahram Saeidi 10 https://orcid.org/0000-0003-4050-3465

\section{References}

1. Murray CJ, Laakso T, Shibuya K, Hill K, Lopez AD. Can we achieve Millennium Development Goal 4? New analysis of country trends and forecasts of under-5 mortality to 2015. Lancet 2007;370:1040-54.

2. United Nations International Children's Emergency Fund (NNICEF). A child under 15 dies every five seconds around the world - UN report [Internet]. New York: UNICEF; 2018 [cited 2019 Jul 31]. Available from: www.unicef.org/press-releases/child-under-15-dies-every-five-secondsaround-world-un-report.

3. World Health Organization. Tobacco and lung health [Internet]. Geneva (Switzerland): World Health Organization; 2019 May [cited 2019 Jul 31]. Available from: https://www.who.int/news-room/events/detail/ 2019/05/31/default-calendar/world-no-tobacco-day.

4. Hug L, Alexander M, You D, Alkema L; UN Inter-agency Group for Child Mortality Estimation. National, regional, and global levels and trends in neonatal mortality between 1990 and 2017, with scenariobased projections to 2030: a systematic analysis. Lancet Glob Health 2019;7:e710-20.

5. Wu X, Lu X, Schneider E, Ahmed JA, Njenga MK, Breiman RF, et al. Reassessment of high prevalence human adenovirus detections among residents of two refugee centers in Kenya under surveillance for acute respiratory infections. J Med Virol 2019;91:385-91.

6. Toivonen L, Forsström V, Waris M, Peltola V. Acute respiratory infections in early childhood and risk of asthma at age 7 years. J Allergy Clin 
Immunol 2019;143:407-10.

7. Rolfhamre P, Grabowska K, Ekdahl K. Implementing a public web based GIS service for feedback of surveillance data on communicable diseases in Sweden. BMC Infect Dis 2004;4:17.

8. GBD 2017 Causes of Death Collaborators. Global, regional, and national age-sex-specific mortality for 282 causes of death in 195 countries and territories, 1980-2017: a systematic analysis for the Global Burden of Disease Study 2017. Lancet 2018;392:1736-88.

9. Omer SB, Sutanto A, Sarwo H, Linehan M, Djelantik IG, Mercer D, et al. Climatic, temporal, and geographic characteristics of respiratory syncytial virus disease in a tropical island population. Epidemiol Infect 2008;136:1319-27.

10. Liu L, Oza S, Hogan D, Perin J, Rudan I, Lawn JE, et al. Global, regional, and national causes of child mortality in 2000-13, with projections to inform post-2015 priorities: an updated systematic analysis. Lancet 2015;385:430-40.

11. Cromley E, McLafferty S. Public participation GIS and community health. GIS Pub Health 2012:411-22.

12. Bian L. Spatial approaches to modeling dispersion of communicable diseases - a review. Transact GIS 2013;17:1-17.

13. Hossain MZ, Bambrick H, Wraith D, Tong S, Khan AF, Hore SK, et al. Sociodemographic, climatic variability and lower respiratory tract infections: a systematic literature review. Int J Biometeorol 2019;63:20919.

14. Błażejczyk K, Baranowski J, Błażejczyk A. Climate related diseases. Current regional variability and projections to the year 2100. Quaest Geogr 2018;37:23-36.

15. GBD 2015 Eastern Mediterranean Region Lower Respiratory Infections Collaborators. Burden of lower respiratory infections in the Eastern Mediterranean Region between 1990 and 2015: findings from the Global Burden of Disease 2015 study. Int J Public Health 2018;63(Suppl 1):97108.

16. Rahbar M, Ahmadi M, Lornejad H, Habibelahi A, Sanaei-Shoar T, Mesdeaghinia A. Mortality causes in children 1-59 months in iran. Iran J Public Health 2013;42(Supple1):93-7.

17. Golding N, Burstein R, Longbottom J, Browne AJ, Fullman N, OsgoodZimmerman A, et al. Mapping under-5 and neonatal mortality in Africa, 2000-15: a baseline analysis for the Sustainable Development Goals. Lancet 2017;390:2171-82.

18. Beatty TKM, Shimshack JP. Air pollution and children's respiratory health: a cohort analysis. J Environ Econ Manag 2014;67:39-57.

19. Sultana M, Sarker AR, Sheikh N, Akram R, Ali N, Mahumud RA, et al. Prevalence, determinants and health care-seeking behavior of childhood acute respiratory tract infections in Bangladesh. PLoS One 2019;14: e0210433.

20. Benincà E, van Boven M, Hagenaars T, van der Hoek W. Space-time analysis of pneumonia hospitalisations in the Netherlands. PLoS One 2017;12:e0180797.

21. Semenza JC, Menne B. Climate change and infectious diseases in Europe. Lancet Infect Dis 2009;9:365-75.

22. Pettifor JM. Acute lower respiratory infections in children. South African J Child Health 2015;9:35.

23. Global Burden of Disease Pediatrics Collaboration, Kyu HH, Pinho C,
Wagner JA, Brown JC, Bertozzi-Villa A, et al. Global and national burden of diseases and injuries among children and adolescents between 1990 and 2013: findings from the global burden of disease 2013 study. JAMA Pediatr 2016;170:267-87.

24. Yu HL, Yang CH, Chien LC. Spatial vulnerability under extreme events: a case of Asian dust storm's effects on children's respiratory health. Environ Int 2013;54:35-44.

25. Analitis A, Katsouyanni K, Biggeri A, Baccini M, Forsberg B, Bisanti L, et al. Effects of cold weather on mortality: results from 15 European cities within the PHEWE project. Am J Epidemiol 2008;168:1397-408.

26. Reiner RC, Welgan CA, Casey DC, Troeger CE, Baumann MM, Nguyen QP, et al. Identifying residual hotspots and mapping lower respiratory infection morbidity and mortality in African children from 2000 to 2017. Nat Microbiol 2019;4:2310-8.

27. Rhoda N, Velaphi S, Gebhardt G, Kauchali S, Barron P. Reducing neonatal deaths in South Africa: progress and challenges. South African Med J 2018;108:9-16.

28. Wu X, Lu Y, Zhou S, Chen L, Xu B. Impact of climate change on human infectious diseases: Empirical evidence and human adaptation. Environ Int 2016;86:14-23.

29. Fayiga AO, Ipinmoroti MO, Chirenje T. Environmental pollution in Africa. Environ Dev Sustain 2018;20:41-73.

30. Brownell M, Enns J. Reducing child mortality in high-income countries: where to from here? Lancet 2018;391:1968-9.

31. Buchan SA, Hottes TS, Rosella LC, Crowcroft NS, Tran D, Kwong JC. Contribution of influenza viruses to medically attended acute respiratory illnesses in children in high-income countries: a meta-analysis. Influenza Other Respir Viruses 2016;10:444-54.

32. Kolifarhood G, Khorasani-Zavareh D, Salarilak S, Shoghli A, Khosravi N. Spatial and non-spatial determinants of successful tuberculosis treatment outcomes: an implication of Geographical Information Systems in health policy-making in a developing country. J Epidemiol Glob Health 2015;5:221-30.

33. Homaie RE, Samadi AH, Bayazidi Y, Hayati R. Comparing the socioeconomic determinants of infant mortality rate in Iran and MENA countries. JEMR 2013;3:135-51.

34. Frey RS, Field C. The determinants of infant mortality in the less developed countries: a cross-national test of five theories. Soc Indic Res 2000;52:215-34.

35. Sonego M, Pellegrin MC, Becker G, Lazzerini M. Risk factors for mortality from acute lower respiratory infections (ALRI) in children under five years of age in low and middle-income countries: a systematic review and meta-analysis of observational studies. PLoS One 2015; 10:e0116380.

How to cite this article: Almasi A, Reshadat S, Zangeneh A, Khezeli M, Teimouri R, Naderi SR, et al. Spatial modeling of mortality from acute lower respiratory infections in children under 5 years of age in 2000-2017: a global study Clin Exp Pediatr 2021;64:632-41. https://doi.org/10.3345/cep.2020.01438 